\title{
Evaluation of a community paramedicine health promotion and lifestyle risk assessment program for older adults who live in social housing: a cluster randomized trial
}

\author{
Gina Agarwal MBBS PhD, Ricardo Angeles PhD, Melissa Pirrie MA, Brent McLeod MPH, Francine Marzanek BSc, \\ Jenna Parascandalo BA, Lehana Thabane MSc PhD
}

Cite as: CMAJ 2018 May 28;190:E638-47. doi: 10.1503/cmaj.170740

See related article at www.cmaj.ca/lookup/doi/10.1503/cmaj.180642

\begin{abstract}
BACKGROUND: Low-income older adults who live in subsidized housing have higher mortality and morbidity. We aimed to determine if a community paramedicine program - in which paramedics provide health care services outside of the traditional emergency response - reduced the number of ambulance calls to subsidized housing for older adults.
\end{abstract}

METHODS: We conducted an open-label pragmatic cluster-randomized controlled trial (RCT) with parallel intervention and control groups in subsidized apartment buildings for older adults. We selected 6 buildings using predefined criteria, which we then randomly assigned to intervention (Community Paramedicine at Clinic [CP@ clinic] for $1 \mathrm{yr}$ ) or control (usual health care) using computer-generated paired randomization. CP@clinic is a paramedicled, community-based health promotion program to prevent diabetes, cardiovascu- lar disease and falls for residents 55 years of age and older. The primary outcome was building-level mean monthly ambulance calls. Secondary outcomes were individual-level changes in blood pressure, health behaviours and risk of diabetes assessed using the Canadian Diabetes Risk Questionnaire. We analyzed the data using generalized estimating equations and hierarchical linear modelling.

RESULTS: The 3 intervention and 3 control buildings had 455 and 637 residents, respectively. Mean monthly ambulance calls in the intervention buildings (3.11 [standard deviation (SD) 1.30] calls per 100 units/mo) was significantly lower $(-0.88,95 \%$ confidence interval $[\mathrm{Cl}]-0.45$ to -1.30$)$ than in control buildings (3.99 [SD 1.17] calls per 100 units/mo), when adjusted for baseline calls and building pairs. Survey participation was $28.4 \%(n=129)$ and $20.3 \%(n=129)$ in the intervention and control buildings, respectively. Residents living in the intervention buildings showed significant improvement compared with those living in control buildings in quality-adjusted life years (QALYs) (mean difference 0.09, $95 \% \mathrm{Cl} 0.01$ to 0.17 ) and ability to perform usual activities (odds ratio 2.6, 95\% Cl 1.2 to 5.8). Those who received the intervention had a significant decrease in systolic (mean change $5.0,95 \% \mathrm{Cl} 1.0$ to 9.0 ) and diastolic (mean change $4.8,95 \% \mathrm{Cl} 1.9$ to 7.6) blood pressure.

INTERPRETATION: A paramedic-led, community-based health promotion program (CP@clinic) significantly lowered the number of ambulance calls, improved QALYs and ability to perform usual activities, and lowered systolic blood pressure among older adults living in subsidized housing. Trial registration: Clinicaltrials.gov, no. NCT02152891 n 2010, chronic disease accounted for $89 \%$ of worldwide deaths, mostly in older adults (65 years of age and older). ${ }^{1}$ It causes a substantial burden on health care systems, including high rates of ambulance calls. ${ }^{2}$ Poorly controlled and undiagnosed hypertension and diabetes are responsible for a substantial proportion of chronic disease burden among older adults.,4 To reduce this burden, improved screening for risk factors is required. ${ }^{5,6}$ In addition, falls contribute to morbidity among older adults, ${ }^{7,8}$ especially those with low socioeconomic status. ${ }^{9}$
Morbidity from cardiovascular diseases, diabetes and falls frequently cause older adults to seek emergency medical care. With the percentage of older adults in Canada expected to increase from $14.6 \%$ (2012) to $24 \%(2036),{ }^{10}$ it is critical that health promotion and preventive programs are evaluated for feasibility and effectiveness to inform future health systems policies.

Older adults with a lower socioeconomic status who live in subsidized housing have higher mortality rates, ${ }^{11}$ and poorer health-related quality of life (HRQoL) ${ }^{12}$ and health because of 
chronic diseases. ${ }^{13}$ Interacting psychosocial and physical factors complicate utilization of community and health care services, and are associated with development of chronic illness and disability. ${ }^{14}$ In Canada, older adults have difficulty accessing family physicians, ${ }^{14}$ and expansion of community paramedicine programs has been recommended. ${ }^{15}$

Community paramedicine is a new field in which paramedics provide health care outside of traditional emergency response. ${ }^{16,17}$ Community Paramedicine at Clinic (CP@clinic) is a communitybased health promotion and disease prevention program in subsidized-housing buildings for older adults. ${ }^{5} \mathrm{~A}$ pilot study of CP@clinic in 1 subsidized building for older adults showed a substantial, clinically important $25 \%$ decrease in ambulance calls. ${ }^{5}$ The objective of our study was to use a randomized controlled trial (RCT) to determine if implementing CP@clinic decreases mean ambulance calls (primary outcome) in intervention versus control buildings, measured at the building level. Secondary outcomes were improvement in risk-factor profiles and HRQOL among older adults living in subsidized community housing (individual-level measures and analysis).

\section{Methods}

\section{Study design and setting}

We conducted an open-label pragmatic cluster RCT with parallel intervention and control groups, in Hamilton, Ontario, between November 2014 and November 2016. The full RCT protocol has been published elsewhere. ${ }^{18}$ Intervention session staffing and daily operations were managed by Hamilton Paramedic Services. All operations were overseen by the McMaster Community Paramedicine Research Team, with advice from local stakeholders (Hamilton Paramedic Service, CityHousing Hamilton and City of Hamilton Housing and Public Health Services).

\section{Participants}

Within intervention buildings, participation in the CP@clinic program was voluntary and accessible by all residents. We obtained written informed consent from participants before collecting any information. We considered data collected only from participants aged 55 years and older for analysis. For the secondary outcomes, we used convenience sampling to recruit survey participants from both intervention and control buildings via posters in common areas and mailed letters.

\section{Inclusion and exclusion criteria}

There were 2 levels of selection: building level and individual participants. Subsidized buildings managed by CityHousing Hamilton were selected using the following criteria: the building was $60 \%$ or more occupied by residents who are 65 years of age or older, had 50 or more apartment units, a matched building with similar characteristics was found, and had a unique postal code. From a total of 22 eligible buildings, 8 medium-to-large buildings (170-536 residential units) met the eligibility criteria and were matched into pairs (1:1) according to geography, number of units, proportion of older adults occupying the building, number of ambulance calls in the previous 2 years and social programming (Table 1). Participants for the pre- and postintervention survey were residents who were 55 years of age and older, who had lived in the building for at least 3 months.

\section{Intervention}

Allocation of intervention occurred at the building level because the intervention was intended for all building residents. For each matched pair of buildings, we used computer-generated paired randomization (www.randomizer.org) to allocate 1 building to receive CP@clinic for 1 year in addition to their usual health care and wellness programs (intervention), while the other building of the pair received usual health care and nonparamedic wellness programs in their building (control).

CP@clinic is a weekly drop-in program that includes assessments of blood pressure, diabetes and risk of falls; health education and promotion; targeted referral to community resources; identification of patients at high risk and referral to health care; and regular communication of participants' health information

Table 1: Building-level characteristics for matched pairs

\begin{tabular}{|c|c|c|c|c|c|c|}
\hline Pair & Building & $\begin{array}{c}\text { Geography } \\
\text { (Statistics Canada divisions) }\end{array}$ & $\begin{array}{l}\text { No. of } \\
\text { units }\end{array}$ & $\begin{array}{l}\text { Percent occupation } \\
\text { by older adults, } 65 \mathrm{yr} \\
\text { of age or older }\end{array}$ & $\begin{array}{l}\text { No. of ambulance } \\
\text { calls per mo in the } \\
\text { previous } 2 \mathrm{yr}, \\
\text { per } 100 \text { units }\end{array}$ & $\begin{array}{l}\text { Social program } \\
\text { availability }\end{array}$ \\
\hline \multirow[t]{2}{*}{1} & 1 & Upper Hamilton & 245 & 96.0 & 3.35 & Well supported \\
\hline & 2 & Upper Hamilton & 170 & 88.9 & 4.04 & Well supported \\
\hline \multirow[t]{2}{*}{2} & 3 & Lower Hamilton & 201 & 88.7 & 3.36 & Limited \\
\hline & 4 & Lower Hamilton & 351 & 75.4 & 3.83 & Limited \\
\hline \multirow[t]{2}{*}{3} & 5 & Lower Hamilton & 244 & 70.1 & 3.03 & Limited \\
\hline & 6 & Lower Hamilton & 200 & 71.2 & 3.73 & Limited \\
\hline \multirow[t]{2}{*}{4} & 7 & Lower Hamilton & 536 & 68.9 & 5.01 & Well supported \\
\hline & 8 & Lower Hamilton & 376 & 50.8 & 3.98 & Well supported \\
\hline
\end{tabular}

*Well-supported buildings had many offerings, such as diabetic clinics, foot care clinics, exercise classes, walking clubs, cooking-for-one classes, mind-body seminars and social activities (e.g., bingo and coffee-tea socials). Limited-support buildings had only 1 or 2 offerings. 
with their family physician..$^{5,19}$ Sessions were held in a common building area by community paramedics who had undergone structured training (online interactive modules and webinar training). Paramedics on modified work assignments (pregnant or temporarily injured/disabled, who cannot perform full paramedic duties) implemented the program because they are well-suited for conducting risk assessments, as well as managing any emergencies that might occur in this vulnerable population.

Paramedics assessed participants using the Canadian Diabetes Risk Questionnaire (CANRISK), ${ }^{20,21}$ which was repeated at 6-month intervals. Participants with a moderate-to-high score on the questionnaire were asked to return for a fasting capillary blood glucose test.

Prespecified algorithms guided paramedics in directing participants to appropriate services. Participants at high risk were referred immediately to appropriate health care services. Participants at moderate risk were referred to community services to assist them in managing their health, specifically targeting risk factors for chronic disease, such as physical inactivity, unhealthy diet, tobacco use, harmful use of alcohol, ${ }^{22}$ mental health and stress. A second consent was required before a participant's assessment results were sent by fax to their family physician; those without were referred to a local agency to help them obtain one. Individuals needing emergency medical attention were directed to urgent care or the emergency department by their own transport or ambulance, as appropriate.

Regular process evaluation assessed trial and implementation fidelity, efficiency, participation rates, compliance and ways to improve the program.

\section{Outcomes}

Our primary outcome was monthly ambulance calls at the building level per 100 apartment units. We collected data for our primary outcome from the paramedic service database. Building ambulance calls were standardized for a building with 100 apartment units to account for different building sizes. Hamilton Paramedic Service had reported an average volume of 3.67 calls per month per standardized building for older adults.

We assessed secondary outcomes (individual level) using the Health Awareness and Behaviour Tool, ${ }^{23}$ specifically developed for use with residents in social housing. It is a compilation of validated questionnaires used in Canada that evaluates health status, knowledge, behaviours and self-efficacy about cardiovascular disease and diabetes, and HRQOL (EQ-5D-3L ${ }^{24}$ converted to quality-adjusted life years [QALYs] using a Canadian value $\left.\operatorname{set}^{25}\right)$. Trained research staff conducted one-on-one interviews in English to complete questionnaires with participants who volunteered. A $\$ 10$ gift card was provided. Our secondary outcomes also included changes in risk factor measures (physical activity, fruits and vegetable intake, body mass index [BMI], waist circumference, HRQoL domains and QALYs.) Body mass index was calculated from self-reported height and weight measured using a scale. Waist circumference was collected using a measuring tape placed at the naval level; if the individual refused, their pant size was requested.

\section{Sample size}

Detecting a difference of 25\% (0.92 ambulance calls per standardized building per mo) between intervention and control groups ( $\alpha=0.05, \beta=0.8$, binomial test) required a sample size of 28 . This effect size is feasible because the pilot study showed a $25 \%$ reduction in calls. ${ }^{26}$ Because the intervention ran for a 12 -month period, the study required 2.3 buildings to provide 28 data points (monthly calls). Because no data were available for estimating an intracluster correlation (ICC) for within-building clustering of monthly ambulance call volume, we used a conservative sample size of 4 intervention buildings and 4 control buildings. There was no published minimum clinically important difference for ambulance calls. Therefore, we consulted with experts at the Hamilton Paramedic Service and determined that $10 \%$ would be an important call reduction.

For our secondary individual outcomes, we estimated the sample size using the CANRISK category, because this was the most representative of overall health behaviour. For a difference of $20 \%$, we needed a minimum of 97 participants from the intervention and control groups ( $\alpha=0.05, \beta=0.8$, difference between proportions).

\section{Statistical analysis}

We report methods and results in accordance with the CONSORT extension to cluster RCTs. ${ }^{27}$ We used descriptive statistics to analyze baseline characteristics of both the clusters and participants. We conducted two levels of analysis: building level (primary outcome: mean monthly ambulance calls) and individual level (secondary outcomes: risk assessments, risk factors, HRQoL).

For the primary outcome, we used generalized estimating equations analysis, adjusted for each building's ambulance call numbers at baseline ( $1 \mathrm{yr}$ before the intervention) and controlled for the pairing of the buildings. ${ }^{28}$ We conducted 2 sets of analyses: in the first analysis, we included 3 pairs of buildings with reliable data (final analysis) and, for the second analysis, we included all randomly assigned buildings, despite 1 building having unreliable data (sensitivity analysis).

For the secondary outcomes, we used general estimating equations for comparing risk factor changes between intervention and control groups, and adjusted for building pairs and clustering by buildings. We performed intention-to-treat principle analysis using multiple imputation to account for missing data owing to dropout or loss to follow-up of participants. ${ }^{29,30}$ We conducted 1 full analysis that included all participants who were present during the preintervention period. In addition, we performed 2 subgroup analyses: the first subgroup analysis involved only residents of intervention buildings who attended the CP@clinic sessions versus the residents of control buildings, with imputation for those with missing data; and the second involved the same comparison but included only participants with post-intervention data.

We used hierarchical linear modelling to assess within individual changes in blood pressure (controlling for clustering of individuals by building) and to identify significant changes across 10 visits via post hoc analysis using least significant differences. All analyses were performed using SPSS version 20 and STATA version 11 . 


\section{Ethics approval}

This study was approved by the Hamilton Integrated Research Ethics Board.

\section{Results}

Of 22 subsidized-housing buildings for older adults managed by CityHousing Hamilton, 8 buildings met our eligibility criteria, providing 4 matched pairs (Figure 1). Characteristics of the matched building pairs are presented in Table 1 . Initially, we included building pairs; however, we excluded 1 pair from final analysis because of an unanticipated inability to obtain the ambulance call data (there was an assisted-living residence adjoined to 1 of the buildings, which we thought could be excluded from ambulance call data, but we discovered post hoc that this was impossible). This came to light soon after the start of the study; however, we decided to continue providing the intervention program to those residents.

The intervention and control buildings had 455 and 637 residents, respectively. The mean participation rate for CP@clinic in the intervention buildings was $37.6 \%(n=171)$, ranging from $14 \%$ to $52 \%$ across buildings.

In both the intervention and control buildings, 129 residents participated in the preintervention Health Awareness and Behaviour Tool survey (Figure 1) to measure the secondary outcomes. Of the residents in the intervention buildings who attended CP@ clinic ( $n=65)$, 59 (90.8\%) completed the postintervention survey and 6 (9.2\%) either moved or died during the study period. Of those who did not attend CP@clinic $(n=64), 19(29.7 \%)$ completed the postintervention survey, 20 (31.2\%) moved or died and 25 (39.1\%) were lost to follow-up. In the control buildings, 59 residents $(45.7 \%)$ completed the postintervention survey, $25(19.3 \%)$ moved or died and 45 (34.9\%) were lost to follow-up. CityHousing Hamilton provided aggregate information about moves and deaths.

Most individual-level sociodemographic and risk factors were similar between the intervention and control groups (Table 2). Smoking rates across the intervention and control buildings differed despite random selection. Other lifestyle-related similar factors did not differ across groups. Baseline characteristics indicated that this population had numerous health-related problems and risk factors. We found that almost half had low education levels, $80 \%$ had inadequate health literacy, more than $50 \%$ had hypertension and more than $23 \%$ self-reported diabetes. Among those without diabetes, nearly all had moderate-to-high risk of developing diabetes, and most had modifiable risk factors. Indicators for HRQoL showed that more than $50 \%$ had problems with mobility, pain or discomfort, and anxiety or depression.

\section{Primary outcome}

There was a significant difference $(p<0.01)$ between the mean number of ambulance calls in the intervention buildings (3.11 [SD 1.30] calls per 100 units/mo and the control buildings (3.99 [SD 1.17] calls per 100 units/mo) in our final analysis (Table 3). This included 3 paired intervention and control buildings. Sensitivity analysis that included all buildings that were randomly assigned initially showed no significant difference between intervention and control buildings. However, the sensitivity analysis was considered unreliable based on the circumstances described. Within-building ICC was 0.06 .

\section{Secondary outcomes}

In the intention-to-treat analysis for all participants who completed the survey during preintervention (Table 4, Table 5). almost all measures were in favour of the intervention participants. Significant differences were noted for QALY and the HRQoL domain measuring ability to engage in "usual activities" ( $p<0.05$ and $p<0.01$, respectively). The subgroup analysis comparing participants in intervention buildings who attended CP@ clinic with participants in control buildings, with imputation for missing data, showed the same results as those for the intentionto-treat analysis with significant improvements $(p<0.01)$ in both ability to engage in usual activities and QALY (Table 6, Table 7). However, complete case analysis (no imputation) showed significant improvements in additional outcomes for those who attended CP@clinic, including changes in CANRISK category and HRQoL "self-care" domain (Appendix 1, available at www.cmaj. ca/lookup/suppl/doi:10.1503/cmaj.170740/-/DC1).

Thirteen $(20.6 \%)$ out of 63 participants in the intervention building with high scores for CANRISK had elevated capillary blood glucose levels ( $\geq 7.0 \mathrm{mmol} / \mathrm{L}$ ), whereas 1 (3.6\%) out of 28 participants with moderate scores had an elevated capillary blood glucose level. This suggests that 14 residents potentially had undiagnosed diabetes, and up to 50 were at high risk of diabetes developing within 10 years.

Out of all participants who attended CP@clinic, 111 (53.9\%) had elevated blood pressure ( $\geq 140 / 90 \mathrm{~mm} \mathrm{Hg}$ ) during their first visit. Thirty-six participants (52.5\%) with no previous diagnosis of hypertension and 75 participants $(54.7 \%)$ of those previously diagnosed with hypertension had elevated blood pressure. While attending CP@clinic, mean blood pressure for these participants decreased significantly by $5.0 \mathrm{~mm} \mathrm{Hg}$ systolic $(95 \% \mathrm{Cl} 1.0$ to 9.0, $p<0.01)$ and $4.8 \mathrm{~mm} \mathrm{Hg}$ diastolic blood pressure $(95 \% \mathrm{Cl} 1.9$ to $7.6, p<0.01)$ after the second and fourth visits, respectively. This decrease was sustained across 10 or more visits. For participants who had elevated blood pressure during their first visit, $43(38.7 \%)$ had normal blood pressure by their second visit (Figure 2), with minimal fluctuation thereafter.

\section{Interpretation}

Our study showed that mean monthly ambulance calls were significantly different between buildings that had CP@clinic and control buildings. We further showed that CP@clinic was effective in improving risk factor profiles and HRQoL of participants. Hypertension and diabetes rates were higher than in an agematched Canadian population. ${ }^{31,32}$ The combination of risk factor improvements among participants was significant enough to show changes in participants' CANRISK category, which implies that CP@clinic is having an impact in reducing participants' risk of developing diabetes. Some HRQoL domains showed significant differences between intervention and control groups. 
Furthermore, participants' blood pressures showed a significant and sustained decrease consistent with previous community blood pressure clinics. ${ }^{33,34}$ All of these individual changes may have led to the significant difference in ambulance calls between intervention and control groups. Extrapolation suggests that an average of 10 to 11 calls per 100 apartment units

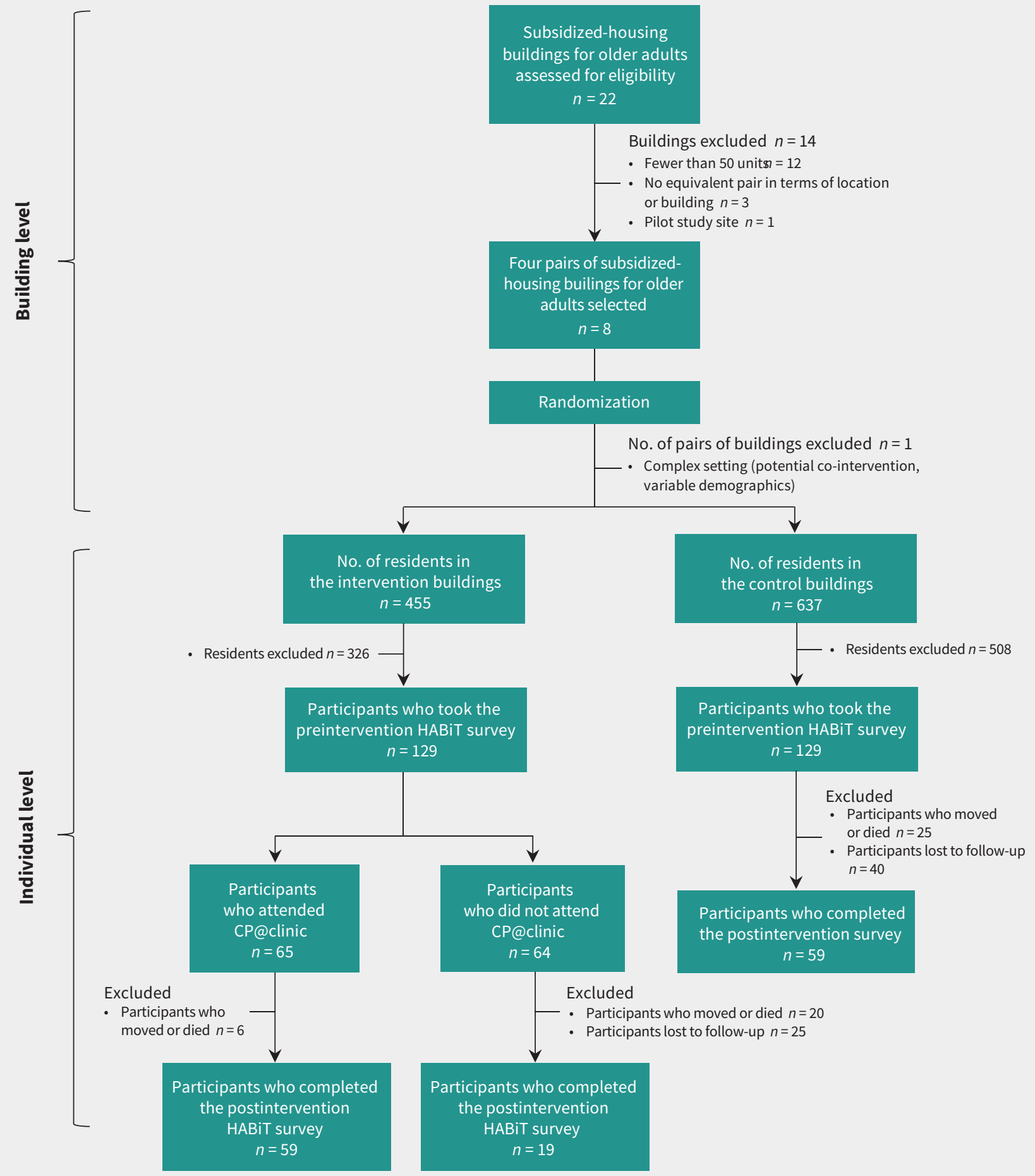

Figure 1: Participant survey and 1-year follow-up. *Most postintervention outcome data for all participants who moved were still available from the CP@clinic database. Note: CP@clinic=Community Paramedicine at Clinic, HABiT= Health Awareness and Behaviour Tool. 
Table 2: Participant-level characteristics for intervention and control buildings at baseline

\begin{tabular}{|c|c|c|}
\hline Characteristic & $\begin{array}{c}\text { No. }(\%)^{\star} \text { of } \\
\text { participants in the } \\
\text { intervention buildings } \\
n=129 \dagger\end{array}$ & $\begin{array}{c}\text { No. }(\%)^{\star} \text { of } \\
\text { participants in the } \\
\text { control buildings } \\
n=129 \dagger\end{array}$ \\
\hline Age, yr; mean \pm SD & $73.7 \pm 8.9$ & $70.9 \pm 8.5$ \\
\hline Female sex & $98(76.0)$ & $95(73.6)$ \\
\hline Lives alone & $115(89.1)$ & $119(92.2)$ \\
\hline \multicolumn{3}{|l|}{ Education level } \\
\hline Some high school or lower & $\begin{array}{c}64(50.8) \\
n=126\end{array}$ & $\begin{array}{c}60(46.9) \\
n=128\end{array}$ \\
\hline High school diploma & $\begin{array}{c}29(23.0) \\
n=126\end{array}$ & $\begin{array}{c}34(26.6) \\
n=128\end{array}$ \\
\hline Some college/university or higher & $\begin{array}{c}16(12.7) \\
n=126\end{array}$ & $\begin{array}{c}14(10.9) \\
n=128\end{array}$ \\
\hline College or university & $\begin{array}{c}17(13.5) \\
n=126\end{array}$ & $\begin{array}{c}20(15.6) \\
n=128\end{array}$ \\
\hline Poor health literacy $\ddagger$ & $80(84.2)$ & $84(81.6)$ \\
\hline \multicolumn{3}{|l|}{ With chronic diseases } \\
\hline Heart problem & $44(34.1)$ & $32(24.8)$ \\
\hline Hypertension & $65(50.4)$ & $73(56.6)$ \\
\hline High cholesterol & $50(38.8)$ & $53(41.1)$ \\
\hline Stroke & $20(15.5)$ & $14(10.9)$ \\
\hline Diabetes & $32(24.8)$ & $41(31.8)$ \\
\hline \multicolumn{3}{|l|}{ Risk factors } \\
\hline Low physical activity & $51(39.5)$ & $71(55.0)$ \\
\hline Low intake of fruits and vegetables & $43(33.3)$ & $41(31.8)$ \\
\hline High intake of alcohol & $2(1.6)$ & $2(1.6)$ \\
\hline Smoker & $25(19.4)$ & $54(41.9)$ \\
\hline High BMI & $83(64.3)$ & $86(66.6)$ \\
\hline \multicolumn{3}{|l|}{ CANRISK score } \\
\hline Moderate & $\begin{array}{c}41(32.5) \\
n=126\end{array}$ & $47(36.4)$ \\
\hline High & $\begin{array}{c}84(66.7) \\
n=126\end{array}$ & $80(62.0)$ \\
\hline \multicolumn{3}{|l|}{ Perceived health status } \\
\hline Reported poor to fair health & $51(39.5)$ & $60(46.5)$ \\
\hline With mobility problems & $76(58.9)$ & $85(65.9)$ \\
\hline With self-care problems & $37(28.7)$ & $20(15.5)$ \\
\hline With problems doing usual activities & $69(53.5)$ & $54(41.9)$ \\
\hline With pain/discomfort & $92(71.3)$ & $104(80.6)$ \\
\hline With anxiety/depression & $64(49.6)$ & $63(48.8)$ \\
\hline Has a family physician & $115(89.1)$ & $122(94.6)$ \\
\hline
\end{tabular}

would be avoided each year. We postulate that the difference in ambulance calls in the short term was due to improved health care access, resource linkage and knowledge about when to access these services.

To date, there have been few rigorous studies that have evaluated community paramedicine programs..$^{35}$ Many of these programs target frequent users of the emergency or health care system. ${ }^{16,36,37}$ In contrast to most community paramedicine programs that focus on the curative aspects of health, CP@clinic has a strong preventive and health promotion component (midstream interventions) that may contribute to enduring lifestyle changes and long-term benefits. Other community paramedicine programs are also more resource intensive, whereas CP@ clinic has proved to be feasible to implement using paramedics on modified work assignments. Furthermore, CP@clinic promotes continuity of care by sharing participants' assessments (with consent) with their family physician and allowing further care to be started by a health care team.

\section{Limitations}

Our study had a few limitations. First, our calculation of sample size was based on an minimum clinically important difference for ambulance calls that we obtained upon consultation with a small number of senior paramedics, and we did not apply an ICC to the calculation, because no ICC estimate was available. To inform future research, we have provided the ICC observed from our data. Second, despite advanced notice that research staff would be in the building with identification, many residents were unwilling to open their doors for one-on-one interviews, out of concern for their safety. The initial plan to recruit by systematic random sampling was later converted to a convenience sampling method to ensure higher participation and better coverage of the building residents. However, our sample demographics were similar to those provided by CityHousing Hamilton for these buildings, with the exception that more women completed the Health Awareness and Behaviour Tool survey $(74.8 \%)$ compared with the overall building residents (59.5\% female). This limitation should be considered when interpreting the study results and when designing future research studies with populations in subsidized housing.

Last, despite our best efforts and multiple follow-ups, a high proportion of participants of the control group and those from the intervention group who did not attend CP@clinic either 


\section{Table 3: Difference in monthly ambulance call rates between intervention and control} buildings

\begin{tabular}{|c|c|c|c|}
\hline \multirow[b]{2}{*}{ Comparison } & \multicolumn{2}{|c|}{ Ambulance call rates per 100 apartment units/mo* } & \multirow[b]{2}{*}{$\begin{array}{l}\text { Mean difference } \\
(95 \% \mathrm{CI})\end{array}$} \\
\hline & $\begin{array}{c}\text { Intervention buildings, } \\
\text { mean } \pm \text { SD }\end{array}$ & $\begin{array}{l}\text { Control buildings, } \\
\text { mean } \pm \text { SD }\end{array}$ & \\
\hline Final analysist & $3.11 \pm 1.30$ & $3.99 \pm 1.17$ & $-0.88(-0.45$ to -1.30$)$ \\
\hline Sensitivity analysisł & $3.68 \pm 1.10$ & $4.01 \pm 0.87$ & $-0.33(-1.32$ to 0.65$)$ \\
\hline
\end{tabular}

\begin{tabular}{|c|c|c|c|}
\hline \multirow[b]{2}{*}{$\begin{array}{l}\text { Quality-of-life measure/ } \\
\text { risk factor domain }\end{array}$} & \multicolumn{2}{|c|}{ No. (\%) of participants with improvement } & \multirow[b]{2}{*}{ OR $(95 \% \mathrm{Cl})$} \\
\hline & $\begin{array}{l}\text { Intervention buildings } \\
\qquad n=129 \dagger\end{array}$ & $\begin{array}{c}\text { Control buildings } \\
n=129 \dagger\end{array}$ & \\
\hline Mobility & $40(31.0)$ & $30(23.3)$ & 1.5 (0.7 to 3.5$)$ \\
\hline Self-care & $29(22.5)$ & $21(16.3)$ & $1.8(0.5$ to 5.8$)$ \\
\hline Usual activities & $43(33.3)$ & $21(16.3)$ & $2.6(1.2$ to 5.8$)$ \\
\hline Pain and discomfort & $44(34.1)$ & $36(27.9)$ & $1.4(0.6$ to 3.0$)$ \\
\hline Anxiety and depression & $57(44.2)$ & $49(38.0)$ & 1.3 (0.8 to 2.3$)$ \\
\hline Physical activity & $21(16.3)$ & $21(16.3)$ & 1.0 (0.5 to 2.2$)$ \\
\hline Intake of fruits and vegetables & $36(27.9)$ & $39(30.2)$ & $0.8(0.1$ to 7.7$)$ \\
\hline CANRISK category & $29(22.5)$ & $16(12.4)$ & 2.0 (0.8 to 5.3$)$ \\
\hline
\end{tabular}

Note: CANRISK = Canadian Diabetes Risk Questionnaire, $\mathrm{Cl}=$ confidence interval, $\mathrm{OR}=$ odds ratio. *Adjusted for pairing and clustering, with imputation.

†Participants who completed the Health Awareness and Behaviour Tool Survey.

\section{Table 5: Comparison of changes in health indicators among participants who attended CP@clinic and participants in control buildings*

\begin{tabular}{|c|c|c|c|}
\hline \multirow[b]{2}{*}{ Health indicator } & \multicolumn{2}{|c|}{$\begin{array}{c}\text { Change in participants from pre- to } \\
\text { postintervention } † \ddagger\end{array}$} & \multirow[b]{2}{*}{$\begin{array}{l}\text { Mean difference } \\
(95 \% \mathrm{CI})\end{array}$} \\
\hline & $\begin{array}{l}\text { Intervention buildings, } \\
\text { mean } \pm \text { SD }\end{array}$ & $\begin{array}{l}\text { Control buildings, } \\
\text { mean } \pm \text { SD }\end{array}$ & \\
\hline BMI & $0.69 \pm 3.6$ & $0.18 \pm 4.7$ & $0.5(-0.4$ to 1.4$)$ \\
\hline Waist circumference, $\mathrm{cm}$ & $4.6 \pm 24.4$ & $-0.4 \pm 14.4$ & $4.4(-1.1$ to 10.0$)$ \\
\hline QALY & $0.15 \pm 0.37$ & $0.06 \pm 0.30$ & $0.09(0.01$ to 0.17$)$ \\
\hline State of healthฯ & $3.9 \pm 26.4$ & $4.3 \pm 35.1$ & $-0.4(-8.4$ to 7.6$)$ \\
\hline \multicolumn{4}{|c|}{$\begin{array}{l}\text { Note: } \mathrm{BMI}=\text { body mass index, } \mathrm{CI}=\text { confidence interval, CP@clinic = Community Paramedicine at Clinic, QALY= quality-adjusted life } \\
\text { year, } \mathrm{SD}=\text { standard deviation. } \\
{ }^{\star} \text { For the those participants who completed the Health Awareness and Behaviour Tool survey. } \\
\text { †Preintervention is defined as the baseline measure immediately before implementing CP@clinic, and postintervention is defined } \\
\text { as } 12 \text { months after the start of CP@clinic in the intervention buildings. } \\
\ddagger \text { Adjusted for pairing and clustering, with imputation. } \\
\text { बVisual analogue scale of } 0-100 \text { in EQ-5D ( } 0=\text { the worst imaginable state of health and } 100=\text { best imaginable state of health). } .^{24}\end{array}$} \\
\hline
\end{tabular}

moved, died or were lost to follow-up. Much of this was reflective of the type of population and beyond our control. ${ }^{38}$ However, participants who attended CP@clinic had a low proportion who moved or died, implying that the intervention may promote individuals to stay in their social housing situations longer. Studies have shown that higher rates may not be significant as long as 


\section{Table 6: Change in health behaviour and quality-of-life outcomes between participants in}

intervention buildings who attended CP@clinic and those in control buildings*

\section{No. (\%) of participants with improvement†}

\section{Quality-of-life measure/ risk factor domain}

Mobility

Self-care

Usual activities

Pain and discomfort

Anxiety and depression

Physical activity

Intake of fruits and vegetables

CANRISK category

\begin{tabular}{ccc}
$\begin{array}{c}\text { Intervention buildings } \\
\boldsymbol{n}=\mathbf{6 5}\end{array}$ & $\begin{array}{c}\text { Control buildings } \\
\boldsymbol{n}=\mathbf{1 2 9}\end{array}$ & OR (95\% CI) \\
\hline $20(30.8)$ & $30(23.3)$ & $1.5(0.5$ to 4.7$)$ \\
$19(29.2)$ & $21(16.3)$ & $2.5(0.4$ to 17.1$)$ \\
$26(40.0)$ & $21(16.3)$ & $3.5(1.5$ to 8.2$)$ \\
$22(33.8)$ & $36(27.9)$ & $1.4(0.5$ to 4.2$)$ \\
$29(44.6)$ & $49(38.0)$ & $1.4(0.4$ to 5.3$)$ \\
$13(20.0)$ & $21(16.3)$ & $1.3(0.6$ to 3.1$)$ \\
$8(12.3)$ & $39(30.2)$ & $0.5(0.0$ to 30.4$)$ \\
$13(20.0)$ & $16(12.4)$ & $1.8(0.7$ to 4.5$)$
\end{tabular}

Note: CANRISK = Canadian Diabetes Risk Questionnaire, $\mathrm{Cl}=$ confidence interval, $\mathrm{CP} @$ clinic = Community Paramedicine at Clinic $\mathrm{OR}=$ odds ratio.

*Among participants who completed the Health Awareness and Behaviour Tool survey.

†With imputation.

Table 7: Comparison of changes in health indicators among participants who attended

CP@clinic and participants in control buildings*

Change in participants from pre- to

postintervention†‡

\begin{tabular}{lccc} 
Health indicator & $\begin{array}{c}\text { Intervention buildings } \\
\text { mean } \pm \text { SD }\end{array}$ & $\begin{array}{c}\text { Control buildings } \\
\text { mean } \pm \mathbf{S D}\end{array}$ & $\begin{array}{c}\text { Mean difference } \\
\mathbf{( 9 5 \% ~} \mathbf{~ I I )}\end{array}$ \\
\hline BMI & $0.3 \pm 2.7$ & $0.2 \pm 4.7$ & $0.1(-0.8$ to 1.0$)$ \\
\hline Waist circumference, $\mathrm{cm}$ & $2.3 \pm 13.7$ & $-0.4 \pm 14.4$ & $-2.7(-1.6$ to 7.0$)$ \\
\hline QALY & $0.22 \pm 0.36$ & $0.06 \pm 0.30$ & 0.16 (0.06 to 0.26) \\
State of healthฯ & $6.8 \pm 21.9$ & $4.3 \pm 35.1$ & 2.4 (-6.0 to 10.9$)$
\end{tabular}

Note: $\mathrm{BMI}=$ body mass index, $\mathrm{Cl}=$ confidence interval, $\mathrm{CP} @$ clinic = Community Paramedicine at Clinic, $\mathrm{QALY}=$ quality-adjusted life year, $\mathrm{SD}=$ standard deviation

${ }^{*}$ For those participants who completed the Health Awareness and Behaviour Tool survey.

†Preintervention is defined as the baseline measure immediately before implementing CP@clinic, and postintervention is defined as 12 months after the start of CP@clinic in the intervention buildings.

tWith imputation.

IVisual analogue scale of $0-100$ in EQ-5D ( $0=$ the worst imaginable state of health and $100=$ best imaginable state of health $){ }^{24}$

the losses are not missing at random. ${ }^{39,40}$ We analyzed the data rigorously using multiple imputation to address this issue of missing data. Although there were fewer outcomes that were significantly different between intervention and control groups in the multiple imputation analysis, the results consistently showed that survey participants of intervention buildings had better outcomes. Furthermore, compared with the control group, participants who attended CP@clinic had significantly worse initial risk factor profiles and HRQoL. If movement were due to death or health problems, participants of CP@clinic should have had a higher proportion of those who moved or died, or were lost to follow-up. This indicates that CP@clinic may have kept participants healthy at home because of the components of the intervention itself or the social effect that it has created in the buildings as noted in our previous study. ${ }^{41}$

\section{Conclusion}

Our study showed that the CP@clinic intervention had a significant effect on mean monthly ambulance calls in the intervention buildings compared with the control buildings. Furthermore, CP@clinic participants showed significantly greater improvement in the CANRISK category and HRQoL domains. There may be long-term effects on ambulance calls. Quantitative and qualitative work is currently being conducted to evaluate this theory in more detail. A scale-up of CP@clinic into similar subsidized-housing buildings across Canada could lead to substantial gains in the health care system and improvements in the health of older adults living in subsidized community housing. In the coming decades, the growing population of older adults will affect the Canadian health system inevitably, and the CP@clinic program has great potential to reduce the impending burden created by this evolving demographic. 


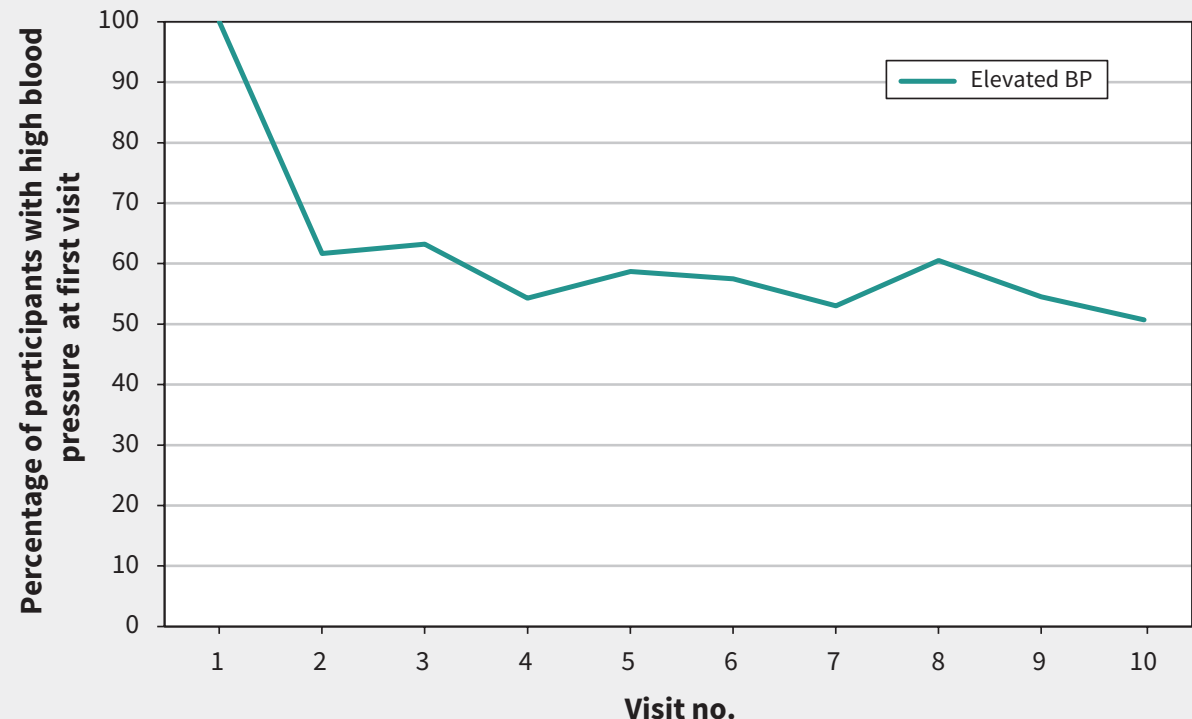

Figure 2: Normalization of blood pressure over time in participants with elevated blood pressure (BP) at the first visit at CP@clinic. Note: CP@clinic=Community Paramedicine at Clinic.

\section{References}

1. Global status report on noncommunicable diseases 2010. Geneva: World Health Organization; 2011.

2. Derlet RW, Richards JR. Overcrowding in the nation's emergency departments: Complex causes and disturbing effects. Ann Emerg Med 2000;35:63-8

3. Global health risks: mortality and burden of disease attributable to selected major risks. Geneva: World Health Organization Press; 2009.

4. Chronic Disease Surveillance and Monitoring Division. Diabetes in Canada: facts and figures from a public health perspective. Ottawa: Public Health Agency of Canada; 2011.

5. Agarwal G, Angeles RN, McDonough B, et al. Development of a community health and wellness pilot in a subsidized seniors' apartment building in Hamilton, Ontario: Community Health Awareness Program delivered by Emergency Medical Services (CHAP-EMS). BMC Res Notes 2015;8:113.

6. Canadian Diabetes Association. Canadian Diabetes Association 2013 clinical practice guidelines for the prevention and management of diabetes in Canada: executive summary. Can J Diabetes 2013;37.

7. WHO Global report on falls prevention in older age. Geneva: World Health Organization Press; 2007.

8. Prevention of falls among the elderly: a special report from the Office of the Provincial Health Officer. Victoria: Ministry of Health Planning; 2004.

9. Series on seniors: seniors and falls. Ottawa: Canadian Institute for Health Information; 2010.

10. Ontario population projections, 2013-2014. Oshawa (ON): Ontario Ministry of Finance. Available: www.fin.gov.on.ca/en/economy/demographics/projections/\#tables (accessed 2018 Jan. 17).

11. Bassuk SS, Berkman LF, Amick BC. Socioeconomic status and mortality among the elderly: findings from four U.S. communities. Am J Epidemiol 2002; 155:520-33.

12. Huguet N, Kaplan MS, Feeny D. Socioeconomic status and health-related quality of life among elderly people: results from the joint Canada/United States survey of health. Soc Sci Med 2008;66:803-10.

13. Gibler K. Aging subsidized housing residents: a growing problem in U.S. cities. J Real Estate Res 2003;22:395-420.

14. Sanders A, Stone R. Supporting aging in place in subsidized housing: an evaluation of the well elder program. Washington (DC): LeadingAge, Center for Applied Research; 2011.

15. Sinha SK. Living longer, living well: highlights and key recommendations. Ontario's Seniors Strategy; 2013.
16. Choi BY, Blumberg C, Williams K. Mobile integrated health care and community paramedicine: an emerging emergency medical services concept. Ann Emerg Med 2016;67:361-6.

17. Ontario expanding community role for paramedics [news release]. Toronto: Ministry of Health and Long-Term Care. 2014 Jan. 21. Available: https://news.ontario. $\mathrm{ca} / \mathrm{mohltc} / \mathrm{en} / 2014 / 01 /$ ontario-expanding-community-role-for-paramedics.html (accessed 2018 Jan. 17).

18. Agarwal G, McDonough B, Angeles R, et al. Rationale and methods of a multicentre randomised controlled trial of the effectiveness of a Community Health Assessment Programme with Emergency Medical Services (CHAP-EMS) implemented on residents aged 55 years and older in subsidised seniors' housing buildings in Ontario, Canada. BMJ Open 2015;5:e008110.

19. Agarwal G, Angeles R, Pirrie M, et al. Effectiveness of a community paramedic led health assessment and education initiative in a seniors' residence building: the Community Health Assessment program through Emergency Medical Services (CHAP-EMS). BMC Emerg Med 2017;17:8.

20. Agarwal G, Kaczorowski J, Hanna S. Community Health Awareness of Diabetes (CHAD): description of a community-wide diabetes awareness demonstration program and its feasibility. Can J Diabetes 2013;37:294-300.

21. Robinson CA, Agarwal G, Nerenberg K. Validating the CANRISK prognostic model for assessing diabetes risk in Canada's multi-ethnic population. Chronic Dis Inj Can 2011;32:19-31.

22. Facing the facts \#1 chronic diseases and their common risk factors. Geneva: World Health Organization; 2005.

23. Agarwal G, McDonough B, Angeles R, et al. Health-related quality of life in older adults residing in subsidized seniors' buildings in Ontario. Proceedings from Trillium Primary Health Care Research Day; 2015 June 2; Toronto.

24. Gusi N, Olivares PR, Rajendram R. The EQ-5D health-related quality of life questionnaire. In: Preedy VR, Watson RR, editors. Handbook of disease burdens and quality of life measures. New York: Springer;2010:87-99.

25. Bansback N, Tsuchiya A, Brazier J, et al. Canadian valuation of EQ-5D health states: preliminary value set and considerations for future valuation studies. PLOS. 2012;7:e31115.

26. NRH notice 03-20: age requirement for senior mandated housing. Thorold (ON): Niagara Regional Housing, 2003. Available: www.nrh.ca/providers/pdf/2003/ NRH-Notice-03-20.pdf (accessed 2017 Nov. 1).

27. Campbell MK, Elbourne DR, Altman DG. CONSORT statement: extension to cluster randomized trials. BMJ 2004;328:702.

28. Hardin JW, Hilbe TM. Generalized estimating equations. 2nd ed. Boca Raton (FL): Chapman and Hall/CRC; 2012. 
29. Little RJA, Rubin DB. Statistical analysis with missing data. Hoboken (NJ): John Wiley \& Sons; 2012.

30. Rubin DB. Multiple imputation after 18+ years. J Am Stat Assoc 1996;91:473-89.

31. Robitaille C, Dai S, Waters C, et al. Diagnosed hypertension in Canada: incidence, prevalence and associated mortality. CMAJ 2012;184:E49-56.

32. Chronic Disease Surveillance and Monitoring Division. Diabetes in Canada: facts and figures from a public health perspective. Ottawa: Public Health Agency of Canada; 2011.

33. Kaczorowski J, Chambers L, Dolovich L, et al. Improving cardiovascular health at population level: 39 community cluster randomised trial of Cardiovascular Health Awareness Program (CHAP). BMJ 2011;342:d442.

34. Ye C, Foster G, Kaczorowski J, et al. The impact of a cardiovascular health awareness program (CHAP) on reducing blood pressure: a prospective cohort study. BMC Public Health 2013;13:1230.

35. Bigham BL, Kennedy SM, Drennan I, et al. Education and practice expanding paramedic scope of practice in the community: a systematic review. Prehosp Emerg Care 2013;17:361-72.
36. Dixon S, Mason S, Knowles E, et al. Is it cost effective to introduce paramedic practitioners for older people to the ambulance service? Results of a cluster randomised controlled trial. Emerg Med J 2009;26:446-51.

37. Abrashkin KA, Washko J, Zhang J, et al. Providing acute care at home: community paramedics enhance an advanced illness management program-preliminary data. J Am Geriatr Soc 2016;64:2572-6.

38. Dupuis-Blanchard S, Neufeld A, Strang V. The significance of social engagement in relocated older adults. Qual Health Res 2009;19:1186-95.

39. Fewtrell MS, Kennedy K, Singhal A, et al. How much loss to follow-up is acceptable in long-term randomised trials and prospective studies? Arch Dis Child 2008;93:458-61.

40. Kristman V, Manno M, Côté P. Loss to follow-up in cohort studies: How much is too much? Eur J Epidemiol 2004;19:751-60.

41. Brydges M, Denton M, Agarwal G. The CHAP-EMS health promotion program: a qualitative study on participants' views of the role of paramedics. BMC Health Serv Res 2016;16:435.

\section{Competing interests: None declared.}

This article has been peer reviewed.

Affiliations: Department of Family Medicine (Agarwal, Angeles, Pirrie, Marzanek, Parascandalo), and Department of Health Research Methods, Evidence, and Impact (Agarwal), McMaster University; Hamilton Paramedic Services (McLeod); Biostatistics Unit (Thabane), St. Joseph's Healthcare Research Institute, Hamilton, Ont.

Contributors: Gina Agarwal, Ricardo Angeles, Brent McLeod and Francine Marzanek were involved in the initial protocol development and study design. Gina
Agarwal, Ricardo Angeles, Melissa Pirrie and Lehana Thabane conducted the statistical analysis. Gina Agarwal, Ricardo Angeles, Melissa Pirrie, Francine Marzanek, Jenna Parascandalo and Lehana Thabane drafted the paper. All of the authors were involved in the conduct of the study, reviewed the manuscript critically for important intellectual conten, gave final approval of the version to be published and agreed to be accountable for all aspects of the work.

Funding: This study was funded by the Hamilton Academic Health Sciences Organization and the Canadian Institutes of Health Research.
Data sharing: De-identified limited data will be shared by the lead author upon request.

Acknowledgements: The authors would like to acknowledge the management and community paramedics of the Hamilton Paramedic Service. The authors would also like to thank CityHousing Hamilton and the City of Hamilton Public Health Services for their support.

Accepted: Mar. 12, 2018

Correspondence to: Gina Agarwal, gina. agarwal@gmail.com 